\title{
JOSEF POLIŠENSKÝ E O SEU INTERESSE PELA HISTÓRIA DAS REGIÕES LUSÓFONAS ${ }^{1}$
}

\author{
por SIMONA BINKOVÁ \\ (Universidade Carolina, Praga)
}

\begin{abstract}
The article deals with the role of Josef Polišenský in the field of propagation of the History of Portugal and the Lusophone countries in Czechoslovakia in the second half of the 20th century, as well as the study of the mutual relations of these countries with the Czech Lands in the course of history.

Key words: Josef Polišenský; History of Portugal and the Lusophone countries; Czechoslovakia; the Czech Lands; Brazil; Portuguese India; university studies; Portuguese studies
\end{abstract}

A extraordinária universalidade do Professor Josef Polišenský como historiador manifestava-se não somente pelo seu interesse na história dos países checos, da Inglaterra, dos Estados Unidos ou dos Países Baixos, mas também de Espanha e das suas colónias na América e no Pacífico. Não em vão é considerado o fundador dos estudos checos modernos na área da história de Espanha e de Hispanoamérica.

O seu interesse orientado originalmente no papel dos países checos, de Espanha e dos Países Baixos na história da Guerra dos Trinta Anos (1618-1648) ia encaminhando-se sob a impressão de acontecimentos coetâneos e de vivências pessoais também rumo a Espanha durante a Guerra Civil espanhola, tal como um pouco mais tarde rumo a história de Cuba e Chile. Não obstante, Polišenský nunca foi um historiador da contemporaneidade propriamente dita, apesar de contemplar, comentar e incluí-la nas sínteses e panoramas da história de distintos países ou territórios inteiros. Com muita maior intensidade e profundidade ocupava-se da história do início da Idade Moderna, no caso de Espanha e da América espanhola, da época colonial até ao século XIX, interessando-se também pelos seus problemas económicos, sociais e pela história das relações mútuas com os países da Coroa da Boémia.

O Professor Polišenský nunca se limitou a factos e acontecimentos isolados, porém, sempre procurou e contemplou as suas interconexões, num contexto mais

1 Este estudo tem como base um artigo em checo escrito faz anos com motivo do falecimento de Josef Polišenský. Ver Simona BINKOVÁ, "Josef Polišenský - iniciátor českého zájmu o dějiny lusofonních oblastî”, in: Ivo Barteček (ed.), Ad honorem Josef Polišenský (1915-2001), Olomouc 2007, pp. 71-74. A presente versão foi actualizada com motivo do centenário de seu natalício e apresentada num colóquio celebrado pelo Centro de Estudos Ibero-Americanos o dia 15 de dezembro de 2015. 
amplo. Desta forma, o estudo que desenvolveu da história dos países de língua espanhola, levou-o consequentemente a dedicar-se também a Portugal e aos seus territórios ultramarinos. A razão disto foi não somente a proximidade geográfica e linguística de ambos os países da Península Ibérica, mas também a história destes, tanto interna como internacional, a qual se desenvolveu com perpétuos confrontos e aproximações repetidas, essencial para a compreensão da evolução da história de cada um deles. Precisamente este esforço para captar e compreender as relações entre os países referidos levou a J. Polišenský a um natural e constante alargamento dos temas da sua investigação. Desta maneira, aproximou-se também à História de Portugal e dos demais países de língua portuguesa.

Os impulsos para um estudo já intencional da história dos países lusófonos ofereceram-se a Polišenský em duas formas: no campo de investigação e no de ensino. Ambas as atividades foram uma parte inerente da sua vida, a partir da época de estudante até aos seus últimos momentos. Dedicou-se à missão docente ainda no período em que foi impedido de dar aulas no Departamento de História Universal por motivos políticos, a partir do princípio dos anos setenta. Naquela situação concentrou o seu esforço em introduzir ou manter o ensino da história dos países respetivos para os estudantes das carreiras filológicas: do neerlandês, do espanhol e também do português. Desta forma, surgiram os seus primeiros materiais didáticos que circularam, ao longo dos anos, pelos estudantes em cópias mecanográficas. Mais tarde, incorporou os ditos materiais no contexto da história da Península Ibérica preparada (em co-autoria com Bohumil Bad'ura e Jiří Kunc dedicados ao século XX) para o prelo como Dějiny Španělska a Portugalska [História de Espanha e Portugal] na casa editorial Svoboda. O projeto, finalizado nos anos 80 , não chegou a realizar-se devido às mudanças políticas no país e ao desaparecimento da casa editorial, e com ela também do manuscrito. A parte que incumbia a Polišenský (desde a pré-história até finais do século XIX) foi publicada finalmente depois de mais de um decénio por empenho de Ivo Barteček, no ano de 1994, pela Universidade de Ostrava, como um texto para o ensino superior Úvod do studia dějin a kultury Španělska a Portugalska. Do přeloти 19. a 20. století [Introdução ao estudo da história e cultura de Espanha e Portugal. Até o século XIX e início do XX]. Já postumamente saiu à luz com o título de Dějiny Iberského poloostrova do přelomu 19. a 20. století [História da Península Ibérica até o século XIX e início do XX] dos autores Polišenský e Barteček também como uma monografia em Olomouc, no ano 2002.

Igualmente, Polišenský incorporava passagens que documentavam a história da América portuguesa ainda nos trabalhos panorâmicos dedicados à América Latina, sendo ele o seu único autor (várias edições de textos universitários em checo Úvod do dějin a kultury Španělska a Latinské Ameriky, em 1963 e 1966, ou em espanhol Introducción a la historia y cultura de España y América Latina, em 1972), ou em co-autoria (Dějiny Latinské Ameriky, 1979). Assim, orientou os leitores a comparar e a confrontar semelhantes ou diferentes rasgos da História de América Latina.

No campo da investigação, o primeiro encontro importante de Polišenský com o mundo lusófono aconteceu provavelmente por ocasião do estudo de um material manuscrito dos princípios do século XVI, encontrado pelo colega eslovaco Peter Ratkoš, na Biblioteca Nacional em Bratislava. Tratava-se de um extenso fragmento 
de um Memorialbuch (Livro de memórias) de Lázaro Nürnberger (Nuremberger) que abarcava cópias de documentos relacionados não somente com os princípios das navegações espanholas ao Caribe, como também com as navegações dos portugueses ao lango da costa africana até à Índia. Aqueles materiais foram acompanhados pelos apontamentos próprios de Nürnberger sobre a sua viagem comercial à Índia no ano de 1517-1518.

Em virtude da colaboração de Josef Polišenský com o indólogo Miloslav Krása e Peter Ratkoš que fez a transcrição, e depois de vários artigos informativos, surgiu uma edição exemplar das passagens mais importantes do manuscrito com o título $E u$ ropean Expansion 1494-1519. The Voyages of Discovery in the Bratislava Manuscript Lyc. 515/8, com o subtítulo Codex Bratislavensis (1986). Nesta edição apareceram transcrições do original em alemão e latim e traduções para o inglês e o português. Os documentos de especial relevância referem-se à segunda navegação de Vasco da Gama à Índia, de 1502 a 1503, escrita por um participante desconhecido, tal como à participação de mercadores alemães no comércio de especiarias. Naquele tempo, Polišenský apoiava já sistematicamente, não só a incorporação do curso de História no ensino da filologia portuguesa, mas também em projetos de investigação do Centro de Estudos Ibero-Americanos fundado por sua iniciativa e de outros colaboradores em 1967 na Faculdade de Filosofia e Letras da Universidade Carolina de Praga.

Nos seminários celebrados com regularidade neste Centro interdisciplinar, aparecia junto aos temas espanhóis e hispano-americanos também a temática de história e cultura desse outro país ibérico e dos seus territórios ultramarinos, como o atesta o próprio nome do Centro, igual como o título do anuário publicado por este, Ibero-Americana Pragensia.

Nesta plataforma apresentavam os resultados das suas investigações também os discípulos e colegas de Polišenský que se ocupavam -sistemática ou ocasionalmente- também da história e cultura dos países lusófonos (Bohumil Bad’ura, Pavel Balcárek, Oldřich Kašpar, Ivo Barteček, Simona Binková e muitos mais na área de história; Zdeněk Hampl, Pavla Lidmilová ou Marie Havlíková no campo da história de literatura; Jaromír Tláskal na esfera da linguística e Pavel Štěpánek na história das artes), sem falar de contribuições de investigadores estrangeiros (p. ex. Luís de Albuquerque, como um dos mais esclarecidos exemplos, veja-se mais abaixo).

Para além disso, a atividade de Polišenský na área de estudos lusitanos manifestou-se por exemplo em ter chamado a atenção para as importantes fontes de náutica e cartografia portuguesas, manuscritas dos séculos XVI e XVII e guardadas na biblioteca da família nobre checa, os Nostitz, em Praga. Em primeiro lugar trata-se de um conjunto de textos e instruções de carácter náutico escrito em português chamado Derrotero que abrange vários roteiros que descrevem a navegação ao redor de África até à Índia, mas também capítulos dedicados aos exames teóricos e práticos dos futuros pilotos, ou também conselhos sobre como curar as doenças no mar. Outro caso foi o Átlas marítimo manuscrito em português e em espanhol que abarcava as costas de todos os continentes conhecidos, acompanhado de plantas de portos importantes e costas adjacentes com as características respetivas (profundidade, ilhotes, areias, etc.). Josef Polišenský travou contacto com a maior autoridade desta problemática, o historiador de ciência náutica e da época dos descobrimentos 
portugueses, Luís de Albuquerque, a quem o enorme interesse pelos valiosos documentos praguenses incitou a visitar Praga pessoalmente em 1989, acompanhado por outros representantes da ciência (Inácio Guerreiro e Martim de Albuquerque) e da esfera editorial portuguesa.

Entretanto, o Professor Polišenský, conforme a intenção de toda a sua vida, envolveu, na tarefa de investigação sobre esses temas, também os seus discípulos e colaboradores (S. Binková, K. Kozická e outros). Resultado disso foram vários estudos referentes aos dois manuscritos anónimos.

Com base numa pesquisa mais detalhada, foi possível datar ambos os manuscritos com maior precisão. O Átlas foi adscrito ao excelente cartógrafo português da primeira metade do século XVII, João Teixeira Albernaz I. É sintomático que os intentos de edição desses materiais sem par no seu género, de enorme valor histórico internacional, e absolutamente apolíticos, tropeçavam ainda durante os anos $80 \mathrm{com}$ a falta de compreensão e hesitação por parte da administração estatal e editorial. Às suas consequências irreparáveis pertence a seguinte perda (furto) do Átlas no início da década de 90 e, independentemente disso, o desvio da maior parte da foto-documentação a cores, devido à desintegração das instituições estatais depois da Revolução de Veludo, em 1989. A reconstrução do extraordinário conjunto cartográfico com base na conservada documentação fotográfica a preto e branco realizou-se só depois de anos de esforço, organizada por um amigo próximo do Prof. Polišenský, o geodesista militar, o Eng. Drahomír Dušátko, e pelo trabalho da investigadora, a autora deste texto, numa tiragem muito limitada. ${ }^{2} \mathrm{O}$ Derrotero teve de esperar até ser publicado por uma casa editorial e pelos investigadores portugueses. ${ }^{3}$

Outro tema de interesse de Josef Polišenský pelo mundo lusófono foi a história do século XVIII e a história das relações checo-portuguesas. Um dos tópicos foi a missão da Coroa Portuguesa à Corte dos Habsburgos em Viena com o fim de negociar o casamento da arquiduquesa Maria Anna (em Portugal mais conhecida por Mariana) com o Rei D. João V, que em 1707 atravessou também os países checos e a sua capital, deixando um testemunho escrito documentando as impressões sobre Praga nos visitantes portugueses. Polišenský revelou igualmente interesse pelas atividades do Pe. Samuel Fritz, jesuíta da Província da Boémia, missionário na Amazónia espanhola, que tendo conhecido pessoalmente a bacia do rio também no seu decurso pelo território correspondente aos portugueses, passou a ser um dos cartógrafos mais reconhecidos do Amazonas, pelo menos até o século XIX. Polišenský prestou atenção também às consequências indiretas do terramoto destructor lisboeta do ano 1755 em Boémia, que repercutiu nos escritos coetâneos sobre as fontes termais da região.

\footnotetext{
[João TEIXEIRA ALBERNAZ I.], Pražský Teixeirův atlas = Teixeira's Prague atlas = Atlas Teixeira praguense, Simona Binková (ed.), Praha, 2004.

3 Artur Teodoro de MATOS - João Manuel TELES E CUNHA (eds.), Livro de Marinharia: o manuscrito de Praga, [s.1.]: EPAL - CEPCEP, 2009. Anteriormente tratou o tema p. ex. Kateřina KOZICKÁ, Pražský rukopis DEROTERO MS c 29 a jeho místo $v$ soudobých portugalských pramenech [O manuscrito praguense DEROTERO MS c 29 e o seu lugar nas fontes coetâneas portuguesas]. Disertação doctoral, Faculdade de Filosofia e Letras, Universidade Carolina, Praha 1994.
} 
Caso semelhante representa a atenção dedicada à repercussão da obra de João Amos Comenius, no Brasil. O Professor Polišenský iniciou e incitou investigação em outros temas, como por exemplo, no ramo moravo dos Silva Tarouca, uma família nobre oriunda de Portugal. Este tema tem vindo a ser estudado por diferentes pontos de vista por Pavel Balcárek, Simona Binková e, ultimamente num contexto mais amplo, por Pavel Štěpánek. ${ }^{4}$

A atenção prestada aos momentos mais importantes das relações históricas entre os dois territórios geograficamente distantes, tal como o interesse sistemático pela problemática brasileira em obras mais complexas, permitem avaliar uma faceta menos conhecida de Polišenský, como iniciador de rigorosos estudos da história dos países lusófonos nos países checos. ${ }^{5}$ Chegou a sê-lo não somente pela obra realizada por ele mesmo, mas também por ter aberto caminho a esta disciplina a outros colegas e seguidores que vão fazendo chegar ao público checo (e em casos de relações bilaterais também ao internacional) o conhecimento da história dessa área linguística e geográfica, ao mesmo tempo que aumenta o interesse pela história dos países lusófonos inclusive de África e Ásia. ${ }^{6}$

(Escrito em português pela autora)

\section{BIBLIOGRAFIA}

BARTEČEK, Ivo - Zdeněk ŠAMBERGER (eds.), Ad honorem Josef Polišenský (1915-2001), Olomouc: Univerzita Palackého, Filozofická fakulta, 2007.

DOMINGUES, Francisco Contente et al., Luís de Albuquerque, historiador e matemático: Homenagem de Amizade a um Homem de Ciência, Lisboa: Chaves Ferreira - Publicações, S.A., 1998.

POLIŠENSKÝ, Josef, Historik v měnícím se světě, Zdeněk Pousta (red.), Praha: Univerzita Karlova, 2001. VAVŘíNEK, Filip, Portugalistika na FF UK: vznik a dějiny oboru, trabalho de bacharelato, Ústav románských studií, FF UK, Praha, 2016.

4 Pavel ŠTĚPÁNEK, Mecenáši Josefa Mánesa: portugalský rod Silva Tarouca a jeho vliv na českou kulturu [Mecenas de Josef Mánes: a família Silva Tarouca e a sua influência na cultura checa]. $1^{\text {a }}$. ed. Olomouc: Univerzita Palackého v Olomouci, 2015; $2^{\mathrm{a}}$. ed. adaptada (bilíngue, em checo e portugûes trad. principal Marie Havlíková), Brno: Nakladatelství K-public, 2016.

5 Na Faculdade de Filosofia e Letras da Universidade Carolina tem-se ensinado a história e cultura de Portugal no marco da filologia portuguesa desde a sua constituição como carreira de licenciatura nos finais dos anos cinquenta do século XX, mas sem especial continuidade. Participaram em impartir o curso (com interrupções) o representante "fundacional" da carreira Zdeněk Hampl (Hampejs), em outros anos Bohumila Mašková de Araújo e nos anos sesenta, o exiliado comunista portugués Flausino Torres (autor do primeiro manual de estudantes titulado História de Portugal: Introdução a civilização e cultura, Praha: SPN, 1970). Depois da sua volta a Portugal tras a caida do regime salazarista e após vários anos de solução provisória (retorno de Z. Hampl), retomou o seu curso Josef Polišenský nos anos setenta e oitenta. Para o contexto compare Filip VAVŘínEK, Portugalistika na FF UK: vznik a dějiny oboru [A filologia portuguesa na Facultade de Filosofia e Letras da Universidade Carolina: o estabelecimento e a história da carreira], trabalho de bacharelato, Praha 2016.

6 Compare as numerosas obras de Jan KLÍMA, Informação bio-bibliográfica a respeito é accesível neste mesmo volume de Ibero-Americana Pragensia, pp. 13-15. Quanto a Ceilão, veja recentemente Karel STANĚK, Sen o novém Portugalsku v tropech. Portugalský pokus o osídlení Šrí Lanky (15801630) [O sonho de novo Portugal nos trópicos. Uma tentativa portuguesa de colonizar Sri Lanka (1580-1630)], Praha: Scriptorium 2017. 


\section{BIBLIOGRAFIA SELECIONADA DE JOSEF POLIŠENSKÝ - HISTÓRIA DOS PAÍSES LUSÓFONOS}

Monografias, partes de monografias e textos de estudante

Úvod do studia dějin a kultury Španělska a Latinské Ameriky [Introdução ao estudo da história e cultura de Espanha e América Latina], texto de estudante, Praha: SPN, 1963; 2a ed. ampliada em Praha: SPN, 1966. Versão em espanhol como Historia y cultura de España y América Latina, Introducción, Praha: SPN, 1972.

Dějiny Latinské Ameriky [História de América Latina], Praha: Svoboda, 1979 (com um coletivo de autores).

European Expansion 1494-1519. The Voyages of Discovery in the Bratislava Manuscript Lyc. 515/8 (Codex Bratislavensis), Prague: Charles University, 1986 (ed. junto com Miloslav Krása e Peter Ratkoš).

Alma Mater Carolina Pragensis. Výbor svědectví cizích návštěvníkü / Charles University and Foreign Visitors, Praha: Univerzita Karlova, 1988, especialmente pp. 57-58. Comentários trilíngues em checo, russo e inglês, documentos nas línguas respectivas (ed. junto com Marie Štemberková).

Česká touha cestovatelská. Cestopisy, deníky a listy ze 17. století [A ânsia boémia de viajar. Livros de viagens, diários e cartas do século XVII], Praha: Odeon, 1989, especialmente pp. 378-405 e 453476 (ed. junto com Simona Binková).

Úvod do studia dějin a kultury Španělska a Portugalska (Do přelomu 19. a 20. století) [Introdução ao estudo da história e cultura de Espanha e Portugal. Até o século XIX e início do XX], texto de estudante, Ostrava: Ostravská univerzita, 1994; edição monográfica como Dějiny Iberského poloostrova do přelomu 19. a 20. století [História da península Ibérica até o século XIX e início do XX], Olomouc: Univerzita Palackého v Olomouci, 2002 (junto com Ivo Barteček).

Tisíciletá Praha očima cizinců [Praga milenária vista por estrangeiros], Praha: Academia, 1999, especialmente pp. 24-28 e 32-33.

\section{Estudos e artigos em revistas ou livros}

"Eine neue Quelle zur zweiten Indienfahrt Vasco da Gamas" [Uma nova fonte para a segunda viagem de Vasco da Gama à Índia], Historica IX, Praha: Academia, 1964, pp. 53-67 (junto com Peter Ratkoš).

"Fuentes para la historia de España y Portugal en los archivos checoslovacos", Ibero-Americana Pragensia IV, Praha: Nakladatelství Karolinum, 1971, pp. 262-267.

“Comenius no Brasil”, Ibero-Americana Pragensia XI, Praha: Nakladatelství Karolinum, 1978, pp. 235-236.

"Centro da Europa, Portugal e a América que leva o nome do Brasil”, Ibero-Americana Pragensia XII, Praha: Nakladatelství Karolinum, 1978, pp. 9-18.

"Codex Bratislaviensis e as suas notícias sobre as viagens portuguesas para a Índia nos anos de 1502 a 1517”, Ibero-Americana Pragensia XII, Praha: Nakladatelství Karolinum, 1978, pp. 173-196 (junto com Peter Ratkoš).

"Uma desconhecida descrição de Praga e da Universidade de Praga do ano de 1707", Ibero-Americana Pragensia XII, Praha: Nakladatelství Karolinum, 1978, pp. 197-202.

"Pedro Fernández de Quirós y su Austrialia", Ibero-Americana Pragensia XV, Praha: Nakladatelství Karolinum, 1981, pp. 155-159 (junto com O. Kašpar).

"Prameny k dějinám portugalských objevných cest v ČSSR" [As fontes para a história dos descobrimentos portugueses na RSCh], Sborník Národního muzea v Praze, Series C, XXIX, Praha: Národní museum, 1984, no. 4, pp. 227-234 (junto com S. Binková). Em português como "As fontes para a história dos descobrimentos portugueses na Checoslováquia”, in: org. de Francisco Contente Domingues e Luís Filipe Barreto, A abertura do mundo. Estudos de história dos descobrimentos europeus, Lisboa: Editorial Presença, 1987, vol. II, pp. 183-189.

“A Boémia e o terramoto de Lisboa de 1755”, Ibero-Americana Pragensia XXXI, Praha: Nakladatelství Karolinum, 1997, pp. 155-159. 


\section{Breve informação sobre a autora}

Simona Binková, diplomada em filologia espanhola, portuguesa e em estudos da língua e literatura checas na Faculdade de Filosofia da Universidade Carolina de Praga, doutorada em História - Estudos Iberoamericanos na mesma Universidade. Dita cursosna mesma, no marco do Centro de Estudos Ibero-Americanos. Além do curso da História colonial de América Latina também cursos da História de Portugal e do Brasil. Especializa-se, entre outro, em temas das relações entre os países checos e a América Latina nos séculos XVI-XIX.

Publicação recente: Simona Binková, Markéta Kř́žová et al., Ir más allá... Fuentes bohemicales para el estudio comparativo de la expansión colonial española en la temprana Edad Moderna (Universidad Carolina, Editorial Karolinum, Praga 2016). Correio electrónico: simona.binkova@ff.cuni.cz 